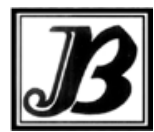

J. Bio-Sci. 24: 1-9, 2016

ISSN 1023-8654

http://www.banglajol.info/index.php/JBS/index

\title{
EFFECT OF DIFFERENT PRUNING OPERATIONS ON THE INCIDENCE AND SEVERITY OF VARIOUS DISEASES OF TEA PLANT
}

\author{
I Ahmad ${ }^{1 *}$, MNA Mamun ${ }^{1}$, MS Islam², R Ara ${ }^{1}$, MAA Mamdud ${ }^{1}$ and AKMR Hoque ${ }^{3}$ \\ ${ }^{1}$ Department of Food Engineering and Tea Technology, Shahjalal University of Science and Technology, \\ Sylhet, Bangladesh; 'BRangladesh Tea Research Institute, Srimangal, Moulvibazar, Bangladesh; ${ }^{3}$ Project \\ Development Unit, Bangladesh Tea Board, Srimangal, Moulvibazar, Bangladesh
}

\begin{abstract}
To analyze the effect of different pruning operation on the incidence and severity of different diseases of tea (Camellia sinensis) plant. An experiment was carried out at the Bilashchara Experimental Farm of Bangladesh Tea Research Institute (BTRI), Srimangal. Three places of the sections were selected randomly that received LP (Light Prune), DSK (deep skiff), MSK (medium skiff) and LSK (light skiff) operations. Every bush was critically observed before and after pruning operations and all infected diseases were recorded. Disease severity was expressed as percent disease index (PDI). MSTAT program was used for statistical snalysis. After pruning operation, maximum incidence $33.33 \%$ and severity $8.20 \%$ of Grey brown blight was found in LSK. Horse hair blight maximum incidence (18\%) and maximum severity (6.27\%) both were found in LSK. In thread blight maximum incidence was in MSK $22.67 \%$ and maximum severity was $7 \%$ in LSK. The highest \% reduction of branch canker both in incidence and severity was observed in LP section followed by DSK, MSK and LSK. In case of Gall disease maximum incidence and severity both was LSK $24.67 \%$ and $7.60 \%$. The highest incidence of black rot was in LSK $41.33 \%$ and severity $12.87 \%$ was in MSK. From the study, it was recommending that without using any chemicals, only by different pruning operations and proper cleaning can reduce the in incidence and severity of those diseases.
\end{abstract}

Key words: Diseases, pruning, pruning cycles, tea

\section{Introduction}

Tea is most widely popular drinking beverage. Bangladesh is a South-Asian country almost bordered by Indian Territory except for a small strip in the South-East by Mayanmar and the Bay of Bengal in the south. The geographical location of tea growing area is restricted only to some green specks between $21030^{\prime}$ and $26015^{\prime}$ north latitude and between $890^{\prime}$ and $92041^{\prime}$ east longitude (Ahmed 2005). Tea cultivation in Bangladesh developed concurrently with the North-east Indian tea during the early part of nineteenth century. Bangladesh tea grows in the three fairly divergent ecological zones namely Surma valley in greater Sylhet, Halda valley in Chittagong and Karatoa valley in Panchagarh districts and most of the tea gardens are situated in Moulavibazar, Sylhet and Chittagong (Ahmed et al. 2015 a,b). Tea ecosystem is a complex agro-ecosystem. It comprises tea, shade trees, green crops, forest etc. The intensive mono culture of a perennial crop like tea over an extensive and contiguous area in apparently isolated ecological zones in Bangladesh has formed virtually a stable ecosystem which provided unlimited opportunity for perpetuation and spread of endemic and introduced diseases (Alam 1999). The architecture of tea plantation, variability of plant types and the systemic interaction of various agro-techniques, intercultural operation etc. imposes a significant impact on development of diseases. The most common foliar diseases of tea in Bangladesh are red rust (Cephaleuros parasiticus), horse hair blight (Marasmius equicrinus), thread blight (Marasmius

*Author for correspondence: iftekharfet.sust@yahoo.com 
pulcher), black rot (Corticium invisum), die back (Colletotrichum gloeosporioides), grey blight (Pestalotia theae), brown blight (Colletotrichum camelliae), blister blight (Exobasidium vexans), Macrophoma (Macrophoma theicola) and gall (Fusarium oxysporum). These fungal diseases are predominant in different tea estates of Bangladesh in different periods of time round the year (Sana 1989). In world tea, about 380 fungal and 1 algal diseases have been recorded. The disease spectrum of Bangladesh tea consists of 1 algal disease, 18 fungal diseases and few epiphytes (Sana 1989). These diseases are hitherto the most common, and may be grouped on the basis of the parts of the plant affected as: 1) foliar diseases, 2) stem diseases, and 3) root diseases. In general, increased plant density will tend to increase leaf surface wetness and leaf surface wetness duration, and so make infection by foliar pathogens more likely (Huber and Gillespie 1992). But, of course, how abiotic stress factors interact to affect plants will be key to understanding climate change effects on plants (Mittler 2006); abiotic stress such as heat and drought may contribute to plant susceptibility to pathogens or it may induce general defense pathways which increase resistance. Singh et al. (2004) reported that trees, which have begun to decline in vigor, yield and size of fruit need pruning to help the restore their condition. Moorman and Roxanne (1999) concluded that comprehensive pruning of branches killed by fungi significantly improves the appearance of Scots pines and dogwoods but does not totally eliminate disease from the trees. The fungi involved can be natural inhabitants on the plants' bark, gaining entry to the plant through wounds or natural openings at any time of the year. Many canker-causing fungi remain latent in the infected tissue until plant resistance responses are suppressed during dormancy or reduced by environmental stress (Schoeneweiss 1975 and 1981, Blodgett and Stanoz 1995, Stanoz et al. 1997). In current investigation it can be concluded the pruning of old and undesirable branches stimulated the growth of new shoots to obtain new fruiting wood. Pruning is an essential cultural operation in tea cultivation that is done to convert the plants into a bushy frame and pruning cycle was defined by Hajra (2001) as the interval of time between two successive prunings. This cultural operation has tremendous influences on the micro climate and disease incidence. Besides, the micro climate change, both in cutting and removing of foliages have manifold effects particularly on the incidence and development of diseases as well as multiplication, perpetuation and dissemination of pathogen. Pruning considered as "at best as necessary evil" (Tubbs 1937) as it both stimulates and control growth. In Bangladesh, four years pruning cycle is practiced in tea gardens those are LP- DSK- MSK- LSK. Longer pruning cycle with light form skiff result is reduction of quality of tea (Ali 1970). In tea plantation, different groups of fungicides like carbendazim, copper oxychloride, copper oxide, copper hydroxide, hexaconazole, propiconazole etc. are used for controlling different tea diseases (Ali and Islam 2014). Pruning is an essential cultural operation of tea cultivation that is done to convert the plants into a bushy frame. This cultural operation has tremendous influences on the micro climate and disease management. Besides, the micro climate change, both in cutting and removing of foliages have manifold effects particularly on removal of diseased parts from the bushes automatically. Primarily it is necessary to know the how much the diseases are reduced both in incidence and severity. With the point of view, this study was undertaken- i) to assess the effect of different pruning operations on the incidence and severity of major tea disease and ii) to determine the suitable pruning operation towards the effective disease management.

\section{Materials and Methods}

The experiment was carried out at the Bilashchara Experimental Farm of Bangladesh Tea Research Institute (BTRI), Srimangal, Moulavibazar during October 2012 to February 2013. There were three places of the sections selected randomly that would be received LP operation. From each place 50 bushes were further randomly selected. This procedure was applied for DSK, MSK and LSK operations. Every bush was critically observed and all infected diseases were recorded as per following scale (Islam and Ali 2010). The observations were taken before and after pruning operations. 


\begin{tabular}{cll} 
Grades & & \multicolumn{1}{c}{ Scale } \\
0 & $:$ & No infection / no disease \\
1 & $:$ & $1-20 \%$ infection \\
2 & $:$ & $21-40 \%$ infection \\
3 & $:$ & $41-60 \%$ infection \\
4 & $:$ & $61-80 \%$ infection \\
5 & $:$ & $>80 \%$ infection
\end{tabular}

Disease severity was expressed as percent disease index (PDI) which was calculated by using following formula (Islam and Ali 2010).

Number of infected bushes

Disease Incidence $(\%)=$

Number of total selected bushes

The experimental data were compiled and analysed statistically using MSTAT program. Data were compared following LSD $(P=0.05)$.

\section{Results}

A total of six diseases like, grey blight, horse hair blight, thread blight, gall, branch canker and black rot were recorded during the experiment. Of the six recorded diseases, Grey blight was found statistically $(P=0.05)$ different in severity for pre pruning operation. Maximum incidence of the disease (82\%) was found in MSK operation which was statistically similar to LP and LSK sections. Highest severity of the disease (51.73\%) was found in DSK receiving section. Lowest incidence $72 \%$ was in DSK and lowest severity was $45.70 \%$ was in LP (Table1). After pruning operation, the incidence in LP and DSK section was found statistically identical. Similar case was seen in MSK and LSK sections. In case of severity after pruning operations, DSK and MSK section showed statistically significant result. Lowest incidence was $26.66 \%$ at DSK and lowest severity was $4.27 \%$ at LP (Table1). The highest reduction both in incidence and severity was observed in LP section followed by DSK, MSK and LSK (Fig.1). Horse hair blight was found statistically $(P=0.05)$ different in severity for pre pruning operation. Highest incidence of the disease (50.67\%) was observed in MSK operation which was statistically similar to LP and DSK operations. Maximum severity of the disease (33.40\%) was found in MSK receiving section. Lowest incidence was $42.67 \%$ at LSK and lowest severity was $27.53 \%$ at LP. After pruning operation, highest incidence (18.00\%) and severity (6.27\%) of the disease were found in LSK receiving section. Lowest incidence and severity were $10.00 \%$ and $2.40 \%$ in LP operation (Table 2). The reduction both in incidence and severity was observed in LP section followed by DSK, MSK and LSK (Fig. 2). In case of Thread blight, maximum incidence (60.66\%) was found in LP operation which was statistically similar to DSK and MSK. Maximum severity of the disease (39.33\%) found in LP receiving section. After pruning, maximum incidence (22.67\%) was found in MSK receiving section. The incidence in LP and DSK section was found statistically identical. Similar case was seen in MSK and LP sections. Highest severity of the disease (7\%) found in LSK receiving section (Table 3). On the other hand graphical figure revealed that highest \% reduction both in incidence and severity was observed in LP section followed by DSK, MSK and LSK (Fig. 3). Gall was found significantly different in severity for pre pruning operation. 
Maximum incidence (86.67\%) was found in LSK operation. The incidence in LP, DSK and MSK section was found statistically identical. Maximum severity of the disease (50.27\%) found in MSK receiving section. Lowest incidence (62.66\%) and severity (38.60\%) were observed in DSK and LSK. After pruning maximum incidence of the disease (24.67\%) was found in LSK operation (Table 4). Accordingly, the highest reduction both in incidence and severity was observed in LP section followed by DSK, MSK and LSK (Fig. 4). Highest incidence (44.67\%) of the branch canker disease was found in LP operation which was statistically similar to MSK and LSK sections. Maximum severity of the disease (41\%) was found in LP receiving section. After pruning operations highest incidence of the disease (39.33\%) was found in DSK operation and maximum severity (12.20\%) was found in LSK receiving section (Table 5). The graphical results (Fig. 5) revealed that highest \% reduction both in incidence and severity was observed in LP section followed by DSK, MSK and LSK. Another important disease Black rot was found statistically $(P=0.05)$ different in both incidence and severity for pre pruning operation. Maximum incidence of the disease (87.67\%) was found in LSK operation while highest severity of the disease (49.40\%) found in MSK receiving section. After pruning maximum incidence of the disease (41.33\%) was found in LSK receiving section. The incidence in LP and DSK section was found statistically identical. Highest severity of the disease (12.87\%) recorded in MSK section. Lowest incidence 16.67\% in LP and lowest severity 7.13\% were observed in DSK (Table 6). Fig. 6 revealed that LP pruning has great impact on the significantly reduction of disease incidence and severity followed by DSK, MSK and LSK.

Table1. Effect of different pruning operations on the incidence and severity of grey blight disease of tea.

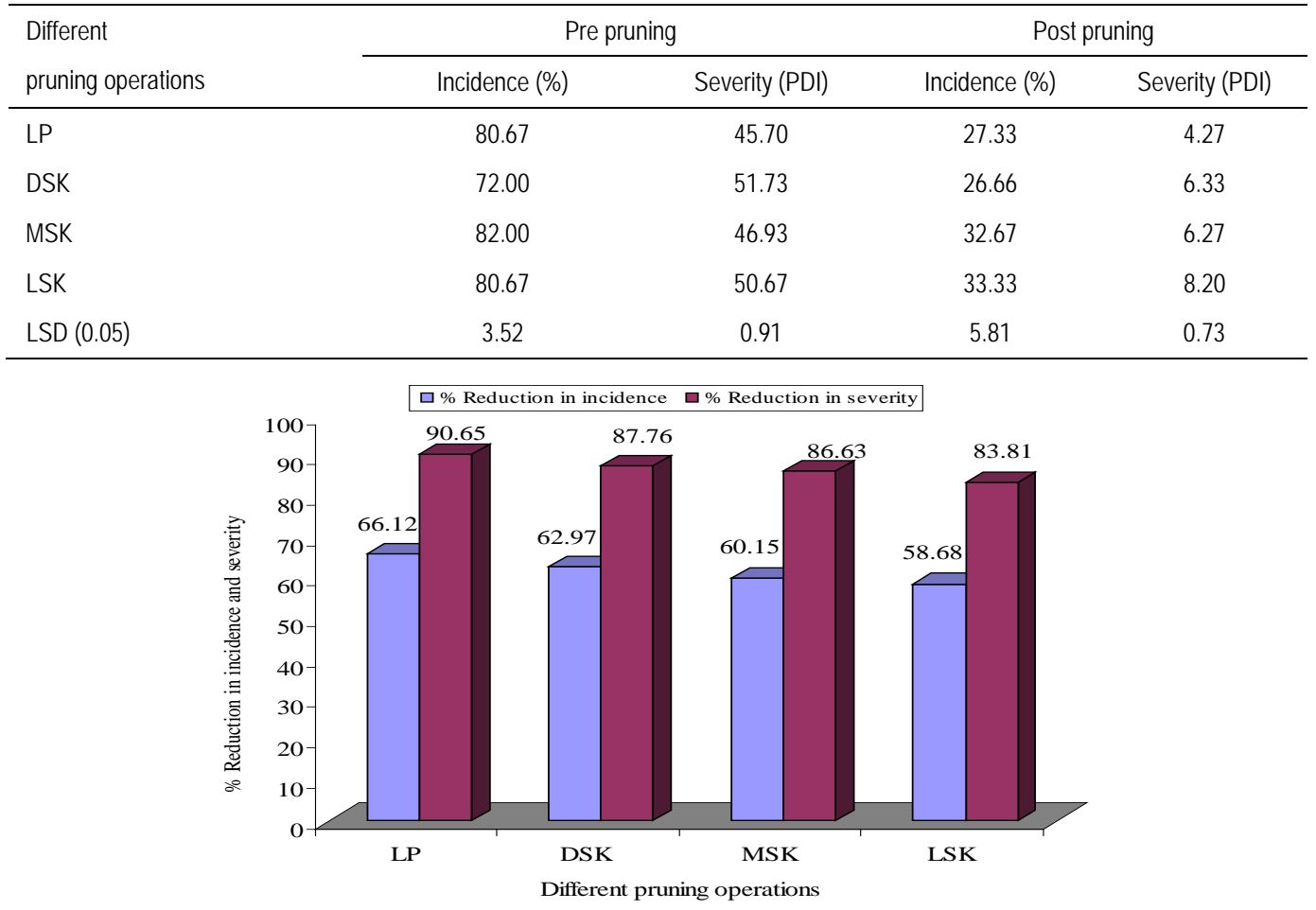

Fig. 1. Showing \% reduction in incidence and severity of grey blight due to pruning operation. 
Table 2. Effect of different pruning operations on the incidence and severity of horse hair blight disease of tea.

\begin{tabular}{lcccc}
\hline Different & \multicolumn{2}{c}{ Pre pruning } & \multicolumn{2}{c}{ Post pruning } \\
\cline { 2 - 5 } pruning operations & Incidence (\%) & Severity (PDI) & Incidence (\%) & Severity (PDI) \\
\hline LP & 45.33 & 27.53 & 10.00 & 2.40 \\
DSK & 49.33 & 31.33 & 13.33 & 3.13 \\
MSK & 50.67 & 33.40 & 14.00 & 5.13 \\
LSK & 42.67 & 27.67 & 18.00 & 6.27 \\
LSD (0.05) & 5.69 & 0.94 & 3.82 & 0.63 \\
\hline
\end{tabular}

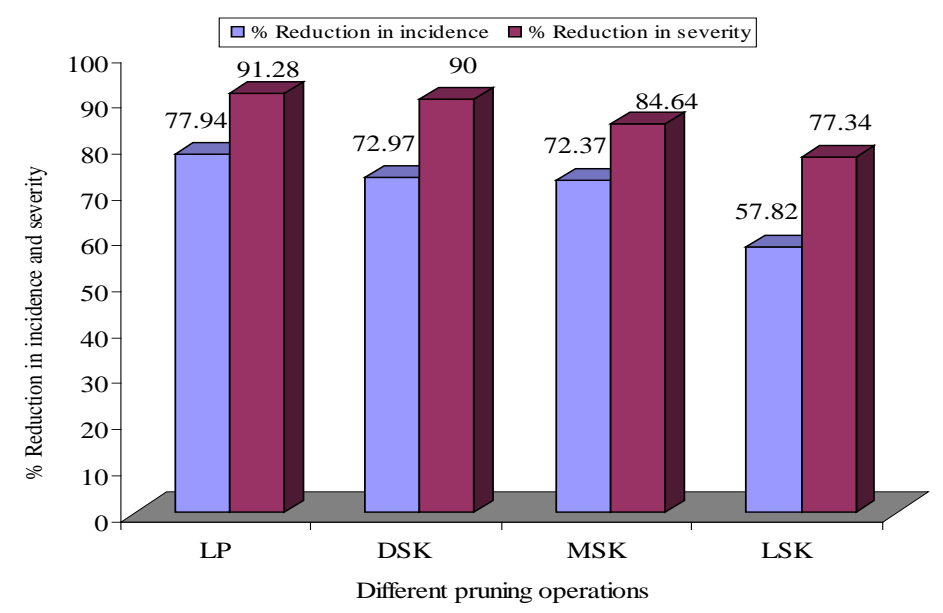

Fig. 2. Showing \% reduction in incidence and severity of horse hair blight due to pruning operations.

Table 3. Effect of different pruning operations on the incidence and severity of thread blight disease of tea.

\begin{tabular}{lcccc}
\hline Different & \multicolumn{2}{c}{ Pre pruning } & \multicolumn{2}{c}{ Post pruning } \\
\cline { 2 - 5 } pruning operations & Incidence (\%) & Severity (PDI) & Incidence (\%) & Severity (PDI) \\
\hline LP & 60.66 & 39.33 & 15.33 & 4.86 \\
DSK & 59.33 & 33.53 & 17.33 & 4.27 \\
MSK & 54.00 & 32.26 & 22.67 & 5.33 \\
LSK & 35.33 & 29.60 & 16.67 & 7.0 \\
LSD (0.05) & 6.89 & 1.12 & 1.33 & 0.68 \\
CV & 6.59 & 1.67 & 3.70 & 7.78 \\
\hline
\end{tabular}




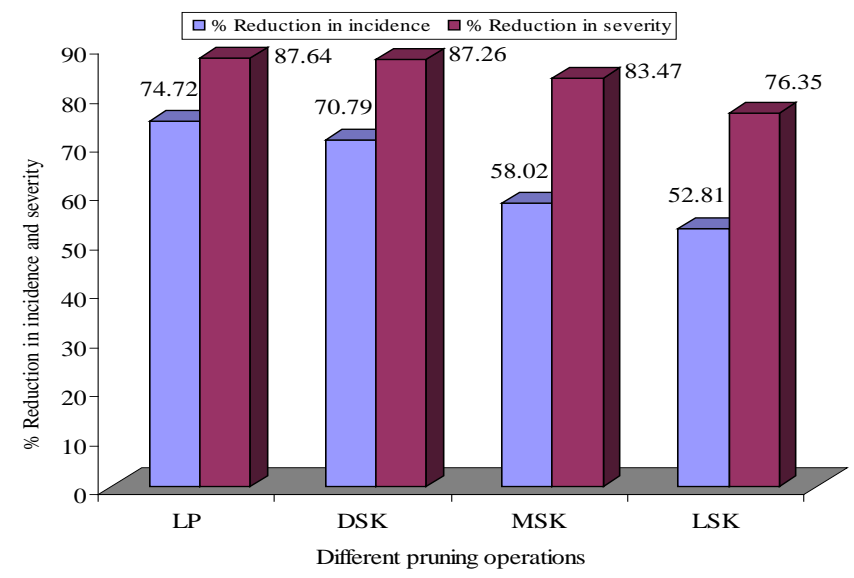

Fig. 3. Showing \% reduction in incidence and severity of threat blight disease due to pruning operations.

Table 4. Effect of different pruning operations on the incidence and severity of gall disease of tea.

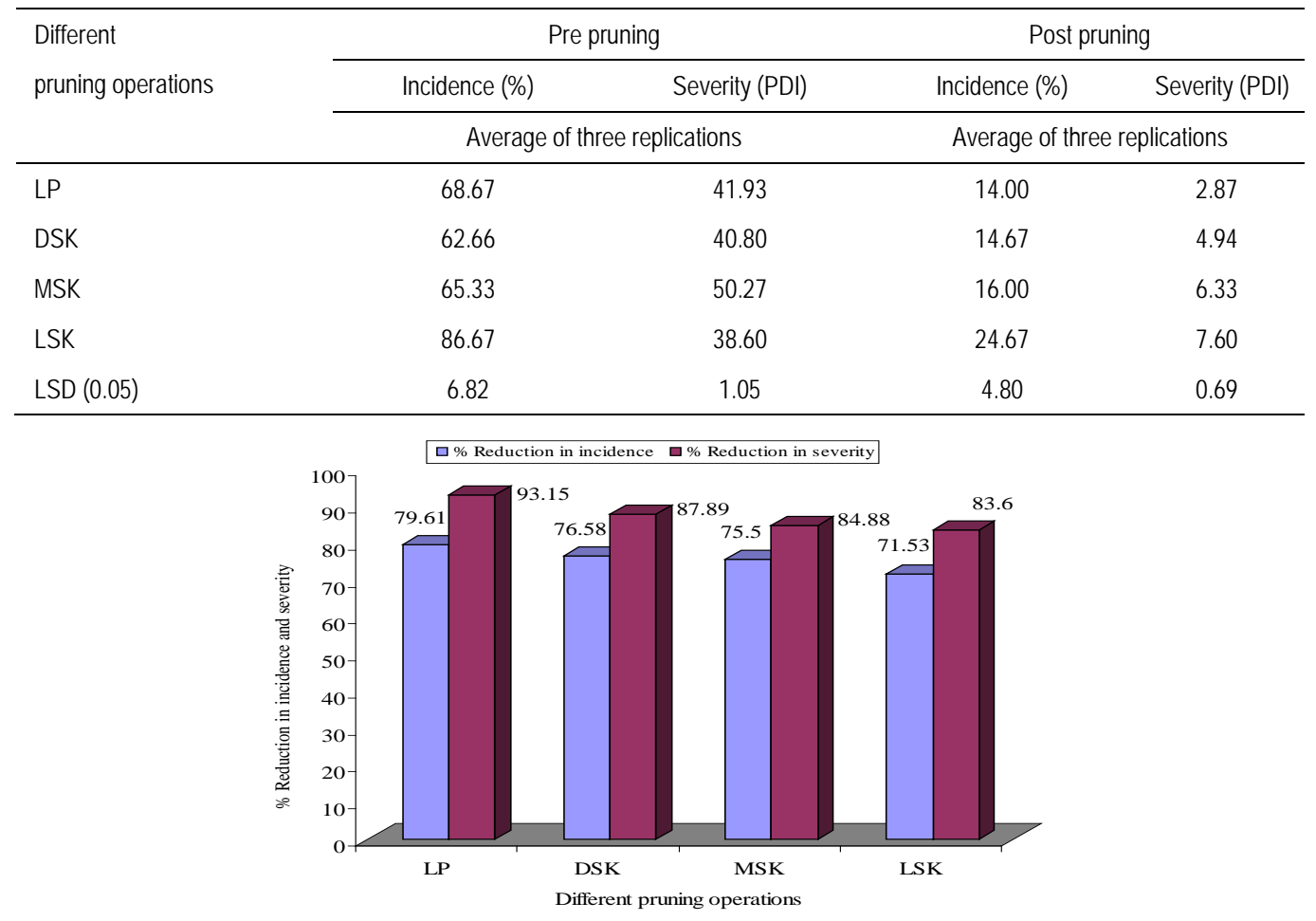

Fig. 4. Showing \% reduction in incidence and severity of gall disease due to pruning operations. 
Table 5. Effect of different pruning operations on the incidence and severity of branch canker disease of tea.

\begin{tabular}{lcccc}
\hline Different & \multicolumn{2}{c}{ Pre pruning } & \multicolumn{2}{c}{ Post pruning } \\
\cline { 2 - 5 } pruning operations & \multicolumn{1}{c}{ Incidence (\%) } & Severity (PDI) & Incidence (\%) & Severity (PDI) \\
\cline { 2 - 5 } & \multicolumn{2}{c}{ Average of three replications } & Average of three replications \\
\hline LP & 44.67 & 41.00 & 27.33 & 10.07 \\
DSK & 28.00 & 24.87 & 39.33 & 8.53 \\
MSK & 43.33 & 26.60 & 34.00 & 10.13 \\
LSK & 40.00 & 24.68 & 35.33 & 12.20 \\
LSD (0.05) & 6.38 & 0.73 & 3.05 & 0.46 \\
\hline
\end{tabular}

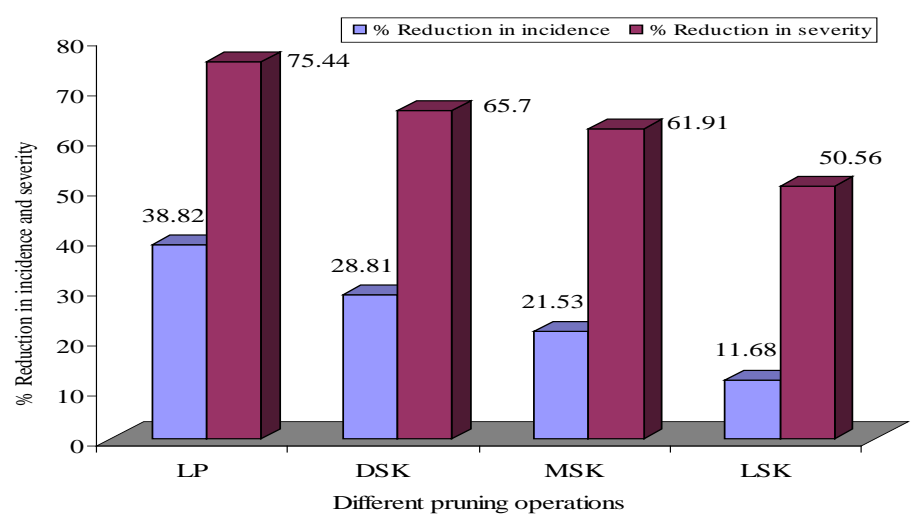

Fig. 5. Showing \% reduction in incidence and severity of canker disease due to pruning operations.

Table 5. Effect of different pruning operations on the incidence and severity of Branch canker disease of tea.

\begin{tabular}{|c|c|c|c|c|c|}
\hline \multirow{3}{*}{$\begin{array}{l}\text { Different } \\
\text { operations }\end{array}$} & \multirow[t]{3}{*}{ pruning } & \multicolumn{2}{|c|}{ Pre pruning } & \multicolumn{2}{|c|}{ Post pruning } \\
\hline & & Incidence (\%) & Severity (PDI) & Incidence (\%) & Severity (PDI) \\
\hline & & \multicolumn{2}{|c|}{ Average of three replications } & \multicolumn{2}{|c|}{ Average of three replications } \\
\hline LP & & 56.00 & 41.73 & 16.67 & 9.80 \\
\hline DSK & & 51.33 & 29.20 & 19.33 & 7.13 \\
\hline MSK & & 70.67 & 49.40 & 29.33 & 12.87 \\
\hline LSK & & 87.67 & 38.73 & 41.33 & 11.67 \\
\hline $\operatorname{LSD}(0.05)$ & & 4.26 & 1.42 & 6.82 & 0.64 \\
\hline
\end{tabular}




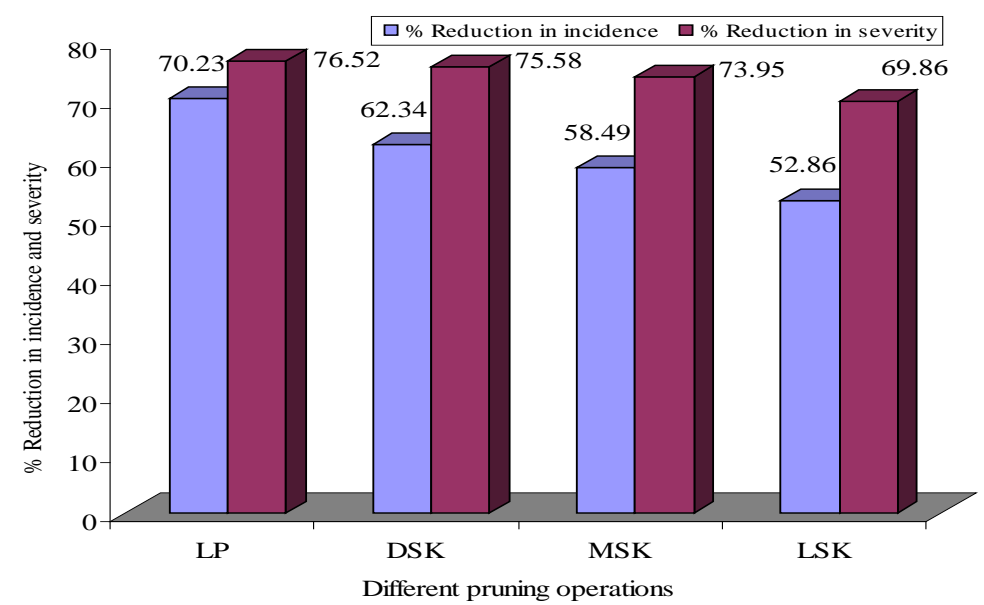

Fig. 6. Showing \% reduction in incidence and severity of black rot disease due to pruning operations.

\section{Discussion}

Pruning entail targeted removal of diseased, damaged, dead, non productive, structurally unsound, or otherwise unwanted tissue from crop. Luepschen and Rohrbach (1969) demonstrated that wound susceptibility of Prunus spp. To Leucostoma spp., the pathogen causing a perennial canker disease of stone fruits, varied by time of year and that the application of shellac was beneficial in reducing infection. Similar benefit of pruning pains to control infection of Malus spp. With Cylindrocarpon mali, another canker disease of apples, have also been demonstrated (Gupta and Agarwala 1972). Biggs (1990) found that wound susceptibility to infection decreases with increasing suberin and lignin formation after wounding. On the other hand Manivel (1980) state that the top layer of maintenance foliage makes the maximum contribution towards the growth of new shouts and as well as reduce the diseases of tea plant. Islam and Ali (2010) observed that the incidence of branch canker to be highest in LP and DSK receiving sections followed by horse hair blight. The incidence of Thread blight disease was found to be comparatively high both in LP and DSK areas. In MSK and LSK receiving sections, Horse hair blight was found to be highest in terms of disease incidence. Similar observation was observed by Uddin et al. (2005) gall disease incidence was low in LP and DSK receiving sections and highest in LSK receiving sections. From the study, it is recommend that without using any chemical only with different pruning operation and proper cleaning can reduce the in incidence and severity of those diseases is possible.

\section{References}

Ahmad I, Hossain A, Rowshan A, Hoque MZ, Miah ML and Ahmed T (2015a). Effect of rainfall on yield and crop distribution of tea. Journal of Global Biosciences 4(5): 2304-2314.

Ahmad I, Yasin M, Rowshon, A and Hoque AKM (2015b). Study on Socio-Economic and Educational condition of Tea Worker at Sylhet in Bangladesh. Journal of Tea Science Research 5(5): 21-27.

Ahmed M (2005). Tea Pest Management. Evergreen Printing, 9/1 Segun Bagicha, Dhaka, 201 pp. 
Alam AFMB (1999). Profile of Tea Industry in Bangladesh. In Global Advances in Tea Science. Araval Books International Ltd., 9 pp.

Ali M and Islam MS (2014). Approved Fungicides and Weedicides for Bangladesh Tea, Bangladesh Tea Research Institute, Srimangal, Moulvibazar. 1-4 pp.

Ali MM (1970). Pruning of tea in Bangladesh, Tea Journal of Bangladesh 8(2): 8-14.

Biggs AR (1990). Managing wound-associated diseases by understanding wound healing in the bark of woody plants, Journal of Arboriculture 16: 108-112.

Blodgett JT and Stanoz GR (1995). Sphaeropsis sapinea and host water stress in a red pine plantation in central Wisconsin, Phytopathology 85: 1044.

Gupta GK and Agarwala RK (1972). Effectivity of wound dressing in the control of apple tree canker (Cylindrocarpon mali), Indian Journal of Mycology and Plant Pathology 2: 91-92.

Hajra NG (2001). Tea cultivation: comprehensive treatise, International Book Distributing Co., 178 pp.

Huber L and Gillespie TJ (1992). Modeling leaf wetness in relation to plant disease epidemiology, Annual review of phytopathology 30(1): 553-577.

Islam MS, Ali M and Ahmad I (2012). Efficacy of sedomil 72WP and recozeb 80WP to control die-back (Colletotrichum gloeosporioides) of tea in Bangladesh, The Journal of Plant Protection Sciences 4(2): 25-31.

Islam MS and Ali M (2010). Incidence of Major Tea Diseases in Bangladesh, Bangladesh Journal of Agricultural Research 35 (4): 605-610.

Luepschen NS and Rohrbach KG (1969). Cytospora canker of peach trees: Spore availability and wound susceptibility, Plant Disease Report 53: 869-872.

Manivel L (1980). Role of maintenance foliage [tea, India], Two and a Bud 3: 45-49.

Mittler R (2006). Abiotic stress the field environment and stress combination. Trends Plant Science 11: 15-19.

Moorman W and Roxanne J (1999). Effects of pruning in the management of Dogwood and Pine Branch Dieback in the landscape, Journal of Arboriculture 25(5): 274-277.

Sana DL (1989). Tea Science. Ashrafia Boi Ghar, Dhaka, 204 pp.

Schoeneweiss DE (1975). A method for controlling plant water potentials for studies on the influence of water stress on disease susceptibility. Canadian Journal of Botany 53: 647-652.

Schoeneweiss, DE (1981). The role of environmental stress in diseases of woody plants, Plant Diseases 65:308-314.

Singh SS, Srivestera VS and Singh P (2004). Training/ pruning, Advances in Citriculture. Kalyani Publisher, Karaataka, India, 206-219 pp.

Stanoz GR, Smith DR, Guthmiller MA and Stanoz JC (1997). Persistence of Sphaeropsis sapinea on or in asymptomatic shoots of red and jack pines, Mycologia 89: 525-530.

Tubbs FR (1937). The length of pruning cycle, Tea Quality 10: 20-36.

Uddin JM, Shahiduzzaman M and Ahmed I (2005). Effect of pruning cycle on the yield of mature tea. International Journal of Sustainable Agriculture 1(16): 82-85. 
